\title{
The influence of selected factors on the load capacity of sewers that are renovated using the relining method
}

\author{
Beata Nienartowicz ${ }^{1, *}$ \\ ${ }^{1}$ Wroclaw University of Science and Technology, Faculty of Civil Engineering, Poland
}

\begin{abstract}
The paper contains the results of a lengthy analysis of the operation of sewers renovated using the relining method. The author based the analysis on the effects obtained from computer simulations that were carried out using the Finite Element Method. The models used to proceed with the FEM simulations were verified by the results obtained from 1:1 laboratory research, conducted by the author over the period 2011-2013. The influence of a few strictly defined factors, related to the cooperation between the liner, injection grout and the construction of the original pipe, were taken into consideration. The report contains the description of FEM simulations and their assumptions, as well as a synthetic analysis of the results.
\end{abstract}

\section{Introduction}

Calculation algorithms contained in such studies as e.g. the German guidelines DWA-A 143-2 [1], the British standard WRC / SRM [2] or the American standard ASTM F1216 [3] are most often used for the dimensioning of elements that reinforce damaged pipelines. Such elements are also known as liners. The existence of many standards and guidelines that contain tips for solving the same type of computational tasks raises the question about differences in the methods and results of calculations, and also about their final impact on investments carried out on their basis. The final results, obtained after calculations with the use of various guidelines, may differ significantly from each other. However, this does not mean that the algorithms used are incorrect, but only that different assumptions were adopted for their creation. Each of the above-mentioned studies contains its own rules regarding, among others, the assessment of the technical condition of the facility to be renovated. They also either include or omit certain aspects of construction work, which in turn may lead to discrepant final calculation results.

A competitive way of designing liners for renovation, which is especially used in atypical and non-standard situations, is computer modelling with the use of the Finite Element Method (FEM). The main advantages of this solution are:

- the possibility of conducting calculations for any geometry of a cross-section and any operating conditions of a conduit,

\footnotetext{
* Corresponding author: beata.nienartowicz@pwr.edu.pl
} 
- the easy comparison of many renovation variants in order to select the most rational solution,

- the possibility of including any system and any changes in soil and water conditions,

- the possibility of identifying the most unfavourable load variant for complicated shapes of a conduit's cross-section.

Conducting a computer analysis, however, imposes the need to meet the extended scope of requirements, including the possession of detailed data on the strength characteristics of construction materials or the characteristics of the soil medium. The results obtained on the basis of the reliably carried out by FEM analyses are very precise and allow the correct liner parameters to be determined without the need to consider significant additional loadbearing capacities.

Designers, when facing such an alternative, choose between computational tools in the form of simple ready-to-use algorithms that give correct but slightly generalized results, or complicated time-consuming and definitely costlier FEM modelling, which is clearly more accurate. All activities that are aimed at extending the scope of knowledge on the functioning of conduits undergoing renovation, as well as the methods of dimensioning liners, were used to bring these solutions closer together and gradually contribute to the improvement of the available algorithms.

This article contains a synthetic description of the analysis carried out by the author regarding the load-bearing capacity of concrete sewage pipes that were damaged to a degree that would prevent their further independent operation and which were then renovated with the use of short relining technology. The aim of the undertaken activities was the identification and qualitative and quantitative analysis of factors that have a direct impact on the liner's bearing capacity after the completion of its renovation.

\section{Investigations and FEM simulations}

\subsection{Main assumptions}

For the needs of the research problem, several types of factors were identified and their impact on the load-bearing capacity of the liners that were used for renovation with the use of relining technology were then subjected to qualititative and quantitative verification. Their final selection, and also definitions, resulted from the analysis of problems closely related to the grouting process involved in short relining technology.

As a result, the following three factors were defined:

1. an increased compressive strength of injection grout,

2. cooperation of the liner with both the grout layer and the construction of the original conduit,

3. cooperation of the liner with the grout.

The full range of tests performed by the author consists of two complementary parts. The first of them was laboratory tests of the models of conduits being renovated, which were made on a 1:1 scale. These tests were carried out on a test stand that was specially constructed for this purpose. The second part included a series of computer simulations of the construction work with the use of FEM. In both parts, laboratory or numerical models of the following three basic types were tested or calculated:

Type I - a model of a concrete conduit in the 3rd technical condition (according to [1]), which is renewed using the short relining method and consists of three elements: the original concrete pipe, a liner made of GRP composite material and grout that fills the assembly gap, 
Type II - a complex model with a construction similar to the type I model but with a smooth outer liner surface,

Type III - a one-element model of a GRP liner.

The Type I and II models are provided in two variants, with IA, IB and also IIA and IIB designations, which indicate the use of grout with different compressive strength values. Two types of grout were adopted: A with compressive strength $f_{c}=28 \mathrm{MPa}$, and B with compressive strenght $f_{c}=1,5 \mathrm{MPa}$.

The load-bearing capacity of a structural element is defined as the maximum permissible load transferred by a structure [4]. Therefore, in both the laboratory tests and FEM simulations, the basic measured value was the value of a load $[\mathrm{kN}]$ that is necessary to induce a vertical displacement of the liner top by a limit value of $10 \%$ of its initial diameter $(50 \mathrm{~mm})$. The method of solving the main research task is presented in Table 1.

Table 1. The method for solving the research task.

\begin{tabular}{|c|c|c|}
\hline No. & Factor & $\begin{array}{c}\text { Verification as well as a qualitative and quantitative } \\
\text { analysis of the impact of the factor on the liner's load- } \\
\text { bearing capacity in the operational phase }\end{array}$ \\
\hline 1. & $\begin{array}{c}\text { The use of injection grout } \\
\text { with an increased } \\
\text { compressive strength } \\
\text { Comparison of the results of tests of the load-bearing } \\
\text { capacity of the GRP panels mounted in two types of } \\
\text { conduit models that were renewed using relining } \\
\text { technology and built with the use of injection grout } \\
\text { with different compressive strength values: } \\
\text { IA / IB types and IIA / IIB types }\end{array}$ \\
\hline 2. & $\begin{array}{c}\text { Cooperation of the liner } \\
\text { with the injection grout and } \\
\text { the construction of the } \\
\text { conduit }\end{array}$ & $\begin{array}{c}\text { Comparison of the results of tests of the load-bearing } \\
\text { capacity of the GRP panels, which were placed directly } \\
\text { in the soil, with the results of tests of the load-bearing } \\
\text { capacity of the GRP panels placed in the models of the } \\
\text { concrete conduits that were renewed using the relining } \\
\text { method: }\end{array}$ \\
Type III / IA, III / IB, III / IIA and III / IIB
\end{tabular}

\subsection{Investigations}

Laboratory tests carried out on a 1:1 scale were an attempt to reproduce the work of a damaged underground concrete pipeline that was undergoing renovation using short relining technology with a liner made of GRP (glass fiber reinforced plastic). The prepared pipeline models were placed in close to real conditions and then subjected to a vertical load until the limit vertical deflection value of the liner, equal to $50 \mathrm{~mm}$, was obtained. Five types of models were built and tested within the framework of this research, each reflecting a rectilinear section of the conduit with a diameter of $600 \mathrm{~mm}$ and a length of $1500 \mathrm{~mm}$.

A detailed description of the research and assumptions adopted for their implementation, as well as a summary and analysis of the obtained results, were presented, among others, in publications [5] and [6]. 


\subsection{FEM simulations}

The main numerical model (2D), which was built within the described task, refers to a concrete pipeline with ground substrate that cooperates with it. The pipeline is in the $3 \mathrm{rd}$ technical condition and is renovated using relining technology. In order to validate the model, three additional numerical auxiliary models were built. One of them was a beam model made of GRP material and subjected to a three-point bending test, and the other two reflected the behaviour of selected laboratory models. The possibility of transparent verification of the work of auxiliary FEM models, based on the obtained research results, enabled a reliable final model with complex characteristics to be constructed. A view of the discrete main numerical model is shown in Figure 1.

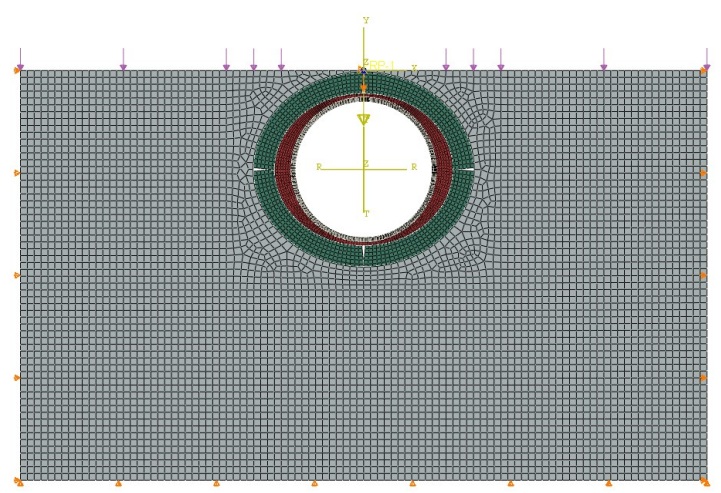

Fig. 1. View of the discrete numerical model.

The following constitutive material models were adopted for the construction of the final model: an elastic-plastic model with the Coulomb-Mohr endurance criterion for the soil, an elastic-perfect plastic model for the GRP liner, and elastic-plastic models with an individual model of concrete and grout failure.

The main numerical model was made in two basic variants, which differed with the widths of the contact zone between the individual fragments of the damaged concrete pipeline. The ratios of the eccentricity of transferring the compressive force in the wall of the structure to the wall thickness $e_{G} / t$ were assumed to be equal to 0.45 and 0.25 . The scheme of the compression zone in the pipeline in the 3rd technical condition, which is defined in accordance with [1], is shown in Figure 2.

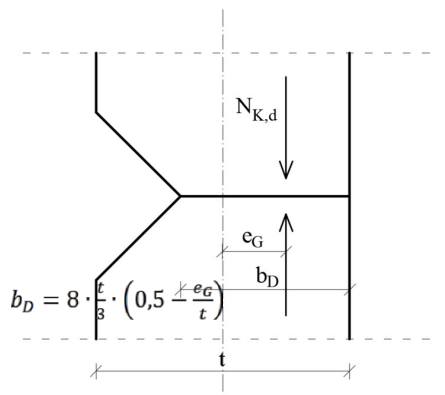

Fig. 2. The diagram of the compression zone, where $t$ - thickness of the pipeline wall, $e_{G}$ - eccentricity of transmission of the compressive force in the pipeline wall, $\mathrm{N}_{\mathrm{k}, \mathrm{d}}$ - compressive force, $\mathrm{b}_{\mathrm{D}}$ - width of the compression zone.

The efficiency of the compression zone is closely related to the compressive strength of the structural material. Its impact on the load-bearing capacity of the original pipeline was 
analysed, among others, by H. Doll [7], who in his work tried to determine the effect of filling the annular gap and cracks in a pipe's wall as the way of transferring compressive forces in a structure. The obtained results showed that the assumption that the layer of grout is only transferring compressive forces does not cause a significant increase in the loadbearing capacity of a renovated structure. However, the use of a grout with an increased tensile strength, and the consideration of the transfer of bending moments by this layer result in a significant reduction of the deformation of a liner.

Guideline [1] defines three states of the compression zone: good, moderate and bad, for which the ratio $e_{G} / t$ is equal to $0.45,0.35$ and 0.25 , respectively. In the case of a bad condition of the compression zone, in objects where it is impossible to determine the actual compressive strength of concrete, the authors of the publication [8] recommend that it should be assumed to be equal to $50 \%$ of the probable initial strength of the material. Therefore, in the described analyses, the following classes of concrete strength of the concrete pipe were used: $\mathrm{C} 40 / 50$ for the variant with $e_{G} / t=0,45$, and $\mathrm{C} 20 / 25$ for the variant with $e_{G} / t=0,25$.

Finally, 18 variants of numerical models, which differ in terms of their construction and material parameters, were calculated. The general characteristics of all the performed simulations are summarized in Table 2.

Table 2. The method for solving the research task.

\begin{tabular}{|c|c|c|c|c|c|c|}
\hline \multicolumn{7}{|c|}{ Basic simulations } \\
\hline No. & $\begin{array}{c}\text { Numerical } \\
\text { model: No. / } \\
\text { variant }\end{array}$ & $e_{G} / t$ & $\begin{array}{c}\text { Concrete } \\
\text { class }\end{array}$ & Grout & $\begin{array}{c}\text { Modulus of } \\
\text { elasticity of GRP }\end{array}$ & $\begin{array}{l}\text { Coefficient } \\
\text { of friction at } \\
\text { the GRP- } \\
\text { grout contact }\end{array}$ \\
\hline S1 & $4 / \mathrm{ak}$ & \multirow{2}{*}{0,45} & \multirow{2}{*}{$\mathrm{C} 40 / 50$} & \multirow{2}{*}{ A } & short-term value & \multirow{2}{*}{0,6} \\
\hline S2 & $4 / a_{L}$ & & & & long-term value & \\
\hline S3 & $4 / b_{K}$ & \multirow{2}{*}{0,45} & \multirow{2}{*}{$\mathrm{C} 40 / 50$} & \multirow{2}{*}{ B } & short-term value & \multirow{2}{*}{0,6} \\
\hline S4 & $4 / b_{L}$ & & & & long-term value & \\
\hline S5 & $4 / \mathrm{cK}_{\mathrm{K}}$ & \multirow{2}{*}{0,45} & \multirow{2}{*}{$\mathrm{C} 40 / 50$} & \multirow{2}{*}{ A } & short-term value & \multirow{2}{*}{0,005} \\
\hline S6 & $4 / c_{L}$ & & & & long-term value & \\
\hline S7 & $4 / d_{K}$ & \multirow{2}{*}{0,45} & \multirow{2}{*}{$\mathrm{C} 40 / 50$} & \multirow{2}{*}{ B } & short-term value & \multirow{2}{*}{0,005} \\
\hline S8 & $4 / d_{L}$ & & & & long-term value & \\
\hline S9 & $4 / \mathrm{e}_{\mathrm{K}}$ & \multirow{2}{*}{0,25} & \multirow{2}{*}{$\mathrm{C} 20 / 25$} & \multirow{2}{*}{ A } & short-term value & \multirow{2}{*}{0,6} \\
\hline $\mathrm{S} 10$ & $4 / \mathrm{e}_{\mathrm{L}}$ & & & & long-term value & \\
\hline S11 & $4 / f_{K}$ & \multirow{2}{*}{0,25} & \multirow{2}{*}{$\mathrm{C} 20 / 25$} & \multirow{2}{*}{ B } & short-term value & \multirow{2}{*}{0,6} \\
\hline $\mathrm{S} 12$ & $4 / \mathrm{f}_{\mathrm{L}}$ & & & & long-term value & \\
\hline $\mathrm{S} 13$ & $4 / g_{K}$ & \multirow{2}{*}{0,25} & \multirow{2}{*}{$\mathrm{C} 20 / 25$} & \multirow{2}{*}{ A } & short-term value & \multirow{2}{*}{0,005} \\
\hline S14 & $4 / g_{L}$ & & & & long-term value & \\
\hline S15 & $4 / h_{K}$ & \multirow{2}{*}{0,25} & \multirow{2}{*}{$\mathrm{C} 20 / 25$} & \multirow{2}{*}{ B } & short-term value & \multirow{2}{*}{0,005} \\
\hline S16 & $4 / h_{L}$ & & & & long-term value & \\
\hline S17 & $2 / \mathrm{ak}$ & \multirow{2}{*}{-} & \multirow{2}{*}{-} & \multirow{2}{*}{ - } & short-term value & \\
\hline S18 & $2 / \mathrm{a}_{\mathrm{L}}$ & & & & long-term value & - \\
\hline
\end{tabular}




\section{Results}

The obtained results indicate that the effect of the increased compressive strength of grout amounts to several percent and can be taken into account when using a liner with either a rough or smooth external surface. The results show a slight increase in the liner's loadbearing capacity when a rough surface is used. The way of including this factor in the design process should be determined individually in relation to the strength parameters of a liner and grout, e.g. based on simple or complex computer simulations.

The influence of the liner's cooperation with both the grout layer and the construction of an original conduit construction can amount to $30 \%$ and includes the influence of factors no. 1 and 3. The method of taking these factors into account in the design process should be determined individually with a detailed consideration of the strength parameters of the applied grout, the occurrence of cooperation between the liner and the grout (smooth or rough liner), the type of material, the strength parameters of the original pipe's construction, the efficiency of the compression zone, as well as the parameters of the surrounding soil and the presence of groundwater. This involves the need to carry out complex computer simulations of construction work, which should be carried out individually for each case. The impact of cooperation between the liner and the grout, although shown in the results of the study, can be considered as negligible in the design of liners.

\section{References}

1. DWA-A 143-2, 2015. Sanierung von Entwässerungsszstemen außerhalb von Gebäuden - Teil 2: Statische Berechnung zur Sanierung von Abwasserleitungen undkanälen mit Lining- und Montageverfahren. Deutsche Vereinigung für Wasserwirtschaft, Abwasser und Abfall

2. WRC/SRM, 2001. 4-th ed. Sewerage Rehabilitation Manual. Swindon: UK Water Research Centre/Water Authorities Association

3. ASTM F-1216, 1998. Standard practice for rehabilitation of existing pipelines and conduits by the inversion and curing of reisin-impregnated tube. Philadelphia: ASTM Designation

4. Popular Encyclopedia, PWN, 2017, PWN Scientific Publishing House

5. C. Madryas, B. Nienartowicz, L. Skomorowski, 2010. Assumptions to investigations of loading capacity of glass reinforced plastic noncircular modules used to renovation of sewerage channels. ITA-AITES, World Tunnel Congress and 36th General Assembly, Vancouver, Canada, May 14-20, 2010 / National Research Council Canada.

6. B. Nienartowicz, 2012. Rehabilitation of sewer channels : investigations of load capacity of channels renovated with GRP liners. Underground infrastructure of urban areas 2 / eds. Cezary Madryas, Beata Nienartowicz, Arkadiusz Szot. Leiden : CRC Press/Balkema, cop. 2012. pp. 185-194.

7. H. Doll, 2010. Sanierung schadhafter Abwasserkanäle mit verdämmten Kunststoffrohren, statische Aspekte, IRO

8. B. Falter, V. Wagner, 2013. Linerdimensionierung nach DWA-A 143-2. Gelbdruck der 2. Auflage des Merkblattes ATV-M 127-2. 3R 03/2013, pp.26-35 